\title{
AGRICULTORES CERTIFICADOS OU EM TRANSIÇÃO ORGÂNICA/AGROECOLÓGICA NO OESTE DO PARANÁ
}

\section{CERTIFIED FARMRS OR IN ORGANIC/ AGRICULTURAL TRANSITION IN THE WEST OF PARANÁ}

\author{
Rodrigo Novakoski \\ Universidade Nova de Lisboa \\ rodrigo.novakoski@hotmail.com \\ Daniela Garcez Wives \\ Universidade Federal do Rio Grande do Sul \\ garcezd@gmail.com
}

\section{Resumo}

Buscou-se pesquisar a agricultura orgânica/agroecológica na região oeste do estado do Paraná. Como objetivo central, este estudo centrou-se nas vivências, dificuldades e os elementos que motivam a agricultura orgânica/agroecológica na região. Para tanto, foram entrevistados vinte e sete agricultores certificados e em transição para a certificação. A pesquisa foi realizada com agricultores nos seguintes municípios: Cascavel, Marechal Cândido Rondon, Palotina, Pato Bragado e São Miguel do Iguaçu. Observa-se que os resultados mais relevantes demonstraram que a agricultura orgânica/agroecológica da região é dependente de políticas públicas, contratos com órgãos governamentais, especialmente a hidrelétrica Itaipu Binacional e contratos com prefeituras. As análises demonstraram que os agricultores atuam para além de seus aspectos prático/teóricos, trazendo a subjetividade como um elo importante para manterem-se como atores ativos nas práticas orgânicas/agroecológicas, por tratar-se, antes de tudo, de um "projeto de vida" em respeito para com o próximo, para não poluir/contaminar o ambiente e para levar alimentos saudáveis aos consumidores.

Palavras-chave: Agricultura orgânica/agroecológica. Políticas públicas. Meio ambiente.

\begin{abstract}
We sought to research organic/ agroecological agriculture in the western region of the state of Paraná. As a central objective, the experiences, difficulties and the elements that motivate organic/ agroecological agriculture in the region were researched. To this end, twenty-seven certified farmers were interviewed and in transition for certification. The research was carried out with farmers in the following municipalities: Cascavel, Marechal Cândido Rondon, Palotina, Pato Bragado and São Miguel do Iguaçu. It is observed that the most relevant results of this research
\end{abstract}


demonstrate that organic / agroecological agriculture in the region is dependent on public policies and contracts with government agencies, especially the Itaipu Binacional hydroelectric plant and contracts with city halls. The analyzes showed that farmers act beyond their practical / theoretical aspects, bringing subjectivity as an important link to remain active players in organic / agroecological practices, since it is, above all, a "project of life "out of respect for others, not to pollute / contaminate the environment and to bring healthy food to consumers.

Keywords: Organic/agroecological agriculture. Public policy. Environment.

\section{Introdução}

Nas últimas duas décadas, houve expressivas mudanças na definição e entendimento das características e da definição do grupo social chamado agricultura familiar (GRISA, 2017; GRISA e SCHNEIDER, 2015; SCHNEIDER e CASSOL, 2014).

Conforme Grisa (2017), Grisa e Schneider (2015) e Schneider e Cassol (2014) a principal mudança que alterou as visões e as representações sobre os camponeses e os agricultores familiares refere-se ao reconhecimento de sua enorme diversidade econômica e heterogeneidade social.

Segundo Schneider e Cassol (2014), as décadas de 1960/1970, acolhiam debates teóricos e referências políticas que almejavam reduzir a diversidade social dos camponeses e agricultores a determinados arquétipos ou padrões de desenvolvimento. $\mathrm{O}$ debate mais atual, no contexto da ressignificação da ruralidade, do reconhecimento da importância e peso das economias locais em relação as lógicas territoriais de desenvolvimento o papel da agricultura familiar ganha força. De acordo com Schneider e Cassol (2014) está transformação não se estabelece na retomada de um debate do qual tratou-se muito no Brasil, calcado na clássica questão sobre o papel da pequena produção no desenvolvimento do capitalismo agrário ou da modernização agrícola. Neste sentido, o foco atual das discussões, segundo com Schneider e Cassol (2014), é centrado em entender por que mesmo depois de décadas de cenários pouco favoráveis, as formas de trabalho e produção familiares não apenas não desapareceram do meio rural, mas em muitas situações conseguiram se fortalecer e mesmo criar novas formas de reprodução social e inserção econômica, como a agroecologia por exemplo". Assim, a agricultura familiar tem vivido constantes demonstrações de enfrentamento frente ao 
modelo produtivo convencional no qual, muitos estão inseridos. Segundo Haverroth (2012), a ineficiência do sistema agroquímico, se dá através de dados e percepções crescentes de insatisfações e incertezas da população rural. Este cenário de incertezas reflete uma crise, com empobrecimento/endividamento do homem no campo, êxodo rural, despovoamento de localidades e também, ambientalmente com a poluição e degradação do solo e contaminação das águas, mostrando-se um modelo excludente e ineficiente.

Diante das contradições da agricultura agroquímica (sintética), a agricultura orgânica/agroecologica passou a ser discutida e (re)construída com base num novo paradigma de agricultura e desenvolvimento rural. Para isso, a reconstrução de formas de produção já existentes e o desenvolvimento de novas tecnologias, levam em consideração complexidade dos sistemas, a inter-relação entre atores de desenvolvimento (técnicos e agricultores e outros), elementos da natureza e fatores econômicos, pretendendo tornar-se sustentável. Ou seja, uma produção agrícola que atenda, em seu processo produtivo, anseios sociais, ambientais e econômicos de maneira satisfatória.

Segundo o Ministério de Agricultura, Pecuária e Abastecimento do Brasil (2016), agricultura orgânica é aquela que produz alimentos in natura ou processados de forma sustentável e não prejudicial ao ecossistema local, e que passaram por um processo de certificação para serem comercializados. Já os conceitos que permeiam o debate sobre a Agroecologia são mais densos e complexos, Altieri (2012) argumenta que a Agroecologia é considerada uma ciência multidisciplinar, a qual integra conhecimentos da área da Sociologia, Antropologia, Economia, Agronomia, Biologia, Ecologia, entre outras, além dos conhecimentos tradicionais desenvolvidos e usados pelos agricultores ao longo da história da agricultura.

Neste sentido a Agroecologia constitui-se como um projeto popular para toda a sociedade, incluindo para além da população camponesa, também a urbana. A importância dessa inter-relação ocorre de forma holística para a superação de desafios comuns, assim essa integração entre diferentes mecanismos da sociedade se torna relevante para a construção da agroecologia de forma ampla e coerente (GONZÁLEZ DE MOLINA, 2009; SEVILLA GUZMÁN, 2006). Dada sua importância perante os acontecimentos na atual situação da agricultura a nível mundial, Caporal (2016) enfatiza 
que a Agroecologia é o único caminho para a construção de agriculturas e novas formas de desenvolvimento rural mais sustentáveis.

A agricultura orgânica e agroecológica ${ }^{1}$ é regimentada pela lei 10.831, de 23 de dezembro de 2003 (BRASIL, 2003), que dispõe sobre a agricultura orgânica. Também é regimentada pela Normativa $\mathrm{n}^{\circ} 46$, de 6 de outubro de 2011, que estabelece o regulamento técnico para os sistemas orgânicos de produção, bem como as listas de substâncias e práticas permitidas para uso nos Sistemas Orgânicos de Produção (BRASIL, 2011).

No entanto, para se chegar à produção orgânica/agroecológica, é necessário um período de transição. O decreto que institui a 'Política Nacional de Agroecologia e Produção Orgânica' define a transição agroecológica como um processo gradual de mudança de práticas e de manejo de agroecossistemas, tradicionais ou convencionais, por meio da transformação das bases produtivas e sociais do uso da terra e dos recursos naturais, que levem a sistemas de agricultura que incorporem princípios e tecnologias de base ecológica. (BRASIL, 2012). Para efeito de certificação, a agricultura orgânica, agroecológica, alternativa ou outras determinações estão submetidas à legislação vigente, além de respeitar a legislação ambiental e trabalhista.

O Paraná é o estado com o maior número de agricultores orgânicos/agroecológicos certificados no Brasil (MAPA, 2019). Muitos deles localizam-se no oeste do Paraná. Nesta região, encontra-se uma realidade peculiar, pela presença do apoio da Itaipu Binacional na promoção de ATER em agricultura orgânica/agroecológica. Estas condições, aliadas às convicções pessoais e às políticas públicas podem ter favorecido a adesão à agricultura orgânica/agroecológica. Ou seja, pelo fato de existirem instituições/ organizações e pessoal técnico comprometidos com o desenvolvimento rural sustentável, dá-se melhores garantias para que ocorra este processo de transição e posterior certificação agroecológica.

A presente pesquisa buscou fazer uma reflexão sobre o desenvolvimento da agricultura orgânica/agroecológica vinculada agricultura familiar, na região oeste do Paraná, elencando os desafios, motivações e oportunidades, no que tange aos aspectos

\footnotetext{
${ }^{1}$ Este trabalho não pretende definir um conceito para a matriz tecnológica de produção de alimentos que não utiliza produtos químico-sintéticos, devido a ampla discussão neste sentido optou-se por referenciar a agricultores, técnicos ou entidades que praticam, promovem e/ou trabalham com a agricultura orgânica/agroecológica.
} 
ecológicos, econômicos e sociais desta atividade. Tal estudo tem como temática central as diferentes percepções da agricultura orgânica/agroecológica, partindo da análise de vivencias de agricultores, extensionistas e instituições públicas/privadas de assistência técnica e extensão rural (ATER), que prestam serviços de promoção à agricultura orgânica/agroecológica.

\section{Metodologia}

Esta pesquisa foi realizada na mesorregião oeste do Paraná, a qual está localizada no Terceiro Planalto Paranaense e abrange uma área de 2.290.859 hectares, correspondendo a cerca de $11,5 \%$ do território estadual. A região faz fronteira com a Argentina e com o Paraguai e possui como principais divisas, os rios Piquiri, Paraná e Iguaçu. A região é formada por 50 municípios, com uma população de 1,3 milhões de habitantes, sendo que 16,8\% da população vive no espaço rural (IPARDES, 2010).

Para este trabalho foram entrevistados agricultores familiares e agricultores assentados nos municípios de Cascavel, Marechal Cândido Rondon, Palotina, Pato Bragado e São Miguel do Iguaçu, no oeste paranaense.

Os métodos utilizados nesta pesquisa estão fundamentados nas abordagens quantitativas e qualitativas, visto que a problemática da pesquisa e os objetivos traçados exigiram a exploração e o tratamento de dados numéricos, bem como a coleta e a interpretação de dados de caráter qualitativo.

A primeira etapa da realização desse estudo foi a obtenção de informações e a coleta de dados secundários com base no Ministério da Agricultura, Pecuária e Abastecimento (MAPA), para a delimitação da área de estudo. O principal critério para a delimitação e a escolha dos municipios pesquisados foi o número de agricultores certificados, limitando-se o estudo aos cinco municípios com maior número de agricultores certificados: Cascavel, Marechal Cândido Rondon, Palotina, Pato Bragado e São Miguel do Iguaçu.

No total, foram entrevistados vinte e sete agricultores certificados ou em processo de transição. O critério utilizado na delimitação e escolha dos agricultores participantes da pesquisa foi a relação que possuíam com a Agroecologia, devendo estar certificados ou em processo de transição. Todas as entrevistas foram gravadas, sendo 
também registradas à mão algumas informações pertinentes, garantindo o desenvolvimento da pesquisa caso houvesse problemas de ordem técnica com o gravador. A pesquisa de campo foi realizada conforme a disponibilidade dos agricultores e das entidades apoiadoras (Cooperativa de Trabalho e Assistência Técnica do Paraná - BIOLABORE, Centro de Apoio e Promoção da Agroecologia - CAPA, Universidade estadual do Oeste do Paraná - UNIOESTE, Instituto Paranaense de Assistência Técnica do Paraná - EMATER e Rede Ecovida), durante os meses de abril, maio, junho, julho, agosto e setembro de 2019.

As entrevistas foram realizadas por meio de um questionário estruturado com perguntas abertas e fechadas, buscado atender aos objetivos da pesquisa. Também foi utilizado o caderno de campo, com reflexões sobre expressões verbais, informações, comentários relevantes, emoções e percepções que surgiram nas observações, além da realização de croquis/desenhos da propriedade, a partir da percepção do agricultor.

Além das entrevistas formais, foram realizadas também visitas e períodos de vivências nas propriedades, buscando evidências e compreensões in loco sobre o processo de desenvolvimento da agricultura orgânica/agroecológica. Por questões éticas, os entrevistados serão identificados apenas com referência ao município de residência do agricultor, preservando suas identidades.

A primeira etapa da análise de dados de campo consistiu na transcrição das entrevistas. Após, as informações foram organizadas, codificadas e tabuladas. A análise dos resultados foi realizada de duas maneiras. No que diz respeito aos dados quantitativos dos resultados gerados para caracterização dos agricultores e das organizações de extensão, fez-se uso do programa Microsoft Excel®, analisando e tabulando os dados (estátistica descritiva), para posterior apresentação em forma de quadros e gráficos.

No que diz respeito aos dados qualitativos, referentes às perguntas abertas, foi utilizada a análise de conteúdo. Conforme explica Vergara (2005), a análise de conteúdo é considerada uma técnica para o tratamento de dados que visa a identificar o que está sendo dito a respeito de determinado tema.

No que tange às etapas para a análise de conteúdo, seguiram-se os passos orientados por Creswell (2009): a exploração e transcrição das entrevistas e anotações de campo; a exploração do material, possibilitando reflexões iniciais sobre os discursos; 
o tratamento dos resultados, inferência e interpretação, ou seja, constitui na codificação ou categorização das respostas, consistindo em um processo de organização do material em segmentos de texto.

\section{Resultados e Discussões}

\section{Caracterização dos agricultores}

Dos vinte e sete agricultores entrevistados, nove são assentados de reforma agrária e dezoito são agricultores familiares. No total, as suas áreas de produção somam 247,9 ha, com média de 9,1 ha/família, e variando entre 0,5 ha (agricultor de Vila Rural) e 35,9 ha. Das vinte e sete famílias, vinte e duas responderam à pergunta sobre se possuem outras propriedades, e todas alegaram não possuir outro imóvel rural. As famílias tiveram acesso à terra, num tempo médio de vinte anos atrás, e buscaram a agricultura orgânica/agroecológica em média de 11,5 anos atrás. $\mathrm{O}$ maior tempo em manejo orgânico/agroecológico encontrado foi de 22 anos e o menor de 1 ano.

No total, foi relatada a presença de setenta e nove pessoas que compunham as famílias, sendo quarenta e três pessoas do sexo masculino e trinta e seis pessoas do sexo feminino, uma média de 2,9 pessoas/família. A maioria, 81,5\% das famílias, não contrata mão de obra externa, os demais, 18,5\%, indicam contratar serviços de mão de obra esporadicamente.

Com relação ao acesso à educação, sessenta e três pessoas responderam aos dados de escolaridade com os níveis: analfabeto (1,59\%), fundamental incompleto $(19,05 \%)$, fundamental completo $(9,51 \%)$, médio incompleto $(12,70 \%)$, médio completo $(34,92 \%)$, superior incompleto $(6,35 \%)$, superior completo $(14,29 \%)$ e PósGraduação (1,59\%). Para melhor representar, expomos os dados no Gráfico 1: 
Gráfico 1 - Nível de escolaridade dos Agricultores e dos membros das suas famílias

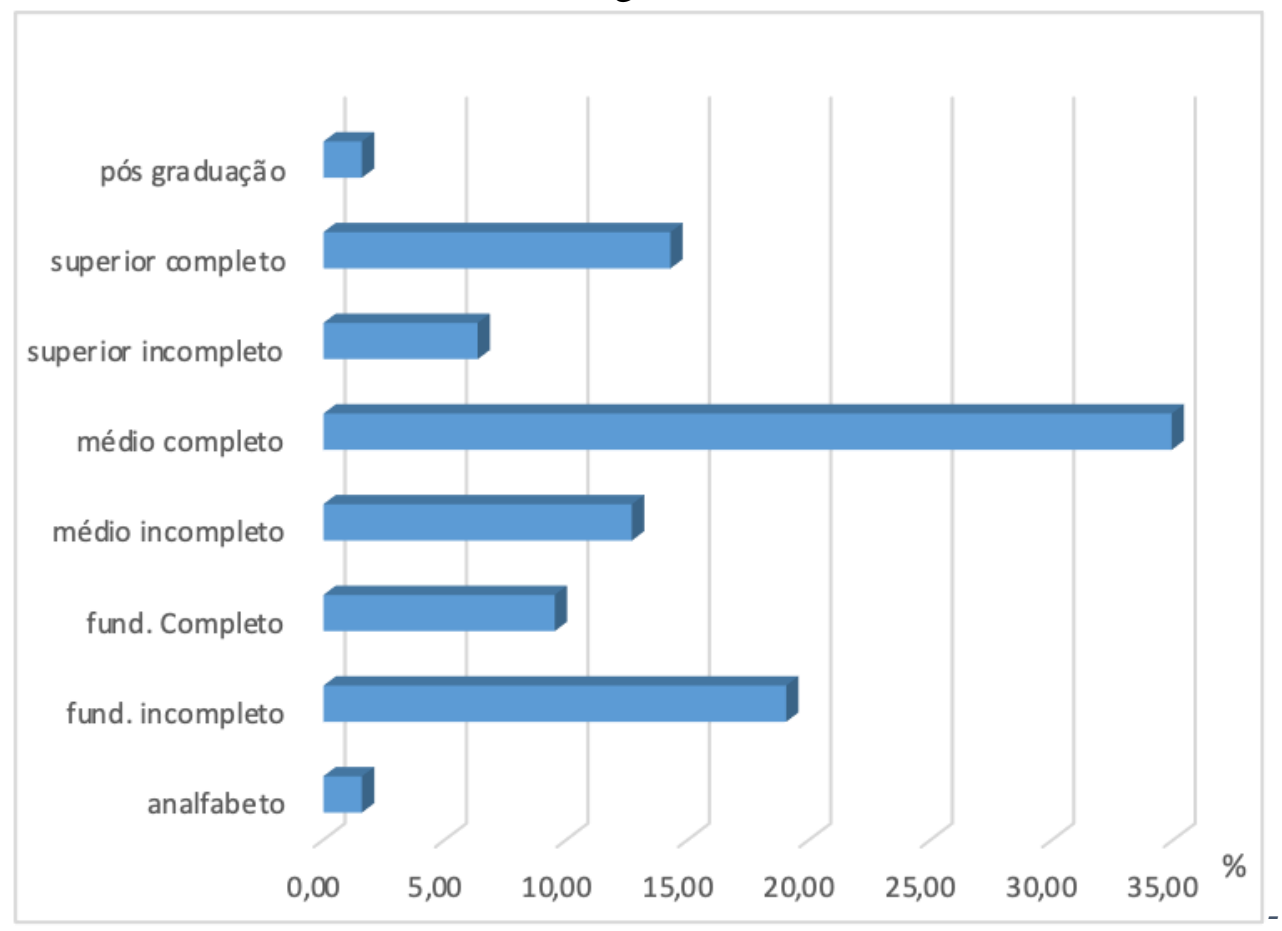

Fonte: O autor (2019).

Das pessoas que tiveram acesso ao ensino superior, cinco estão em áreas de assentamento e quatro são agricultores familiares. A pessoa que fez pós-graduação é agricultor familiar. Segundo Martinelli, Armstrong e Cordeiro (2016), pesquisando vinte e dois agricultores membros da Associação de Produtores Orgânicos de Palotina (APOP), constatou-se que 38\% haviam concluído o ensino fundamental, e $45 \%$ haviam concluído o ensino médio, níveis estes, maiores do que os encontrados neste estudo.

Para dados comparativos, a taxa de analfabetismo no Brasil é de 9,02\%, no estado esta taxa é de 5,78\%, em 2010. Na faixa sem instrução e Ensino Fundamental incompleto, no Paraná, em 2010, foram contabilizados 62,5\% pertencentes a esta faixa. Com relação a faixa instrução mais elevada, o estado do Paraná contabilizou 34,6\% nessa faixa de instrução (IPARDES, 2010).

A respeito da moradia, foram encontrados imóveis de alvenaria, de madeira e mistos, com 55,6\%, 29,6\% e 14,8\% das famílias residindo, respectivamente, em cada tipo de residência. Destas moradias, $80,8 \%$ possuem sanitários dentro da casa e 19,2\% das moradias possuem sanitário do lado externo, anexo à casa. Nenhuma família utiliza sanitário externo do tipo "casinha", também conhecido como patente. Tal fato é relevante, por demonstrar um avanço nas questões sanitárias no meio rural. 
Com relação ao destino do esgoto, observou-se que 77,8\% das famílias utilizam fossas negras, as quais podem causar problemas de contaminação do lençol freático. As demais, $18,5 \%$ utilizam fossa séptica e 3,7\% utilizam a rede pública de esgoto, pois residem em meio urbano. As respostas sobre o destino do lixo doméstico (plástico, papel) foram: reciclagem, queima, coleta pública e enterrar, cujos resultados alcançaram $48,2 \%, 25,9 \%, 22,2 \%$ e $3,7 \%$ respectivamente para cada item. Observa-se que a queima de lixo ainda é uma prática comum, demonstrando haver inadequação com a legislação ambiental, bem como a dificuldade de destino do mesmo. Ao lixo orgânico são dados dois destinos, sendo 96,3\% destinado a compostagem e 3,7\% destinado à coleta pública.

$\mathrm{O}$ acesso à água para consumo nas residências provém de rede pública, poço artesiano, poço comum, mina protegida e mina desprotegida. A maioria das famílias, 44,3\%, consome água, essencialmente, de poço artesiano; em seguida, 37,3\% dos agricultores utilizam água essencialmente de rede pública, 7,3\%, de mina desprotegia, e ainda, essencialmente de poço comum ou, de duas fontes, como rede pública e poço artesiano e rede pública e mina protegida, cada um representando 3,7\% respectivamente. Salienta-se, portanto que, 59\% das famílias não têm acesso à água tratada para consumo.

Para uso na agricultura (lavoura e pecuária), a água vem da rede pública, poço artesiano, poço comum, mina protegida, mina desprotegida e cursos d'água (córregos, riachos). Mesmo com a necessidade de adequar-se à legislação ambiental, 29,6\% das famílias utilizam como fonte de água, córregos e riachos para a agropecuária, associada ou não a outras fontes, como rede pública, mina protegida, mina desprotegida, poço comum e poço artesiano. O poço artesiano, como única fonte de água, representa 40,8\% das fontes para agropecuária. As demais fontes juntas representam 29,6\% da fonte de água para a agropecuária, sendo elas, a rede pública, mina protegida, mina desprotegida e poço comum, usadas exclusivamente ou em conjunto entre elas.

Para que o agricultor seja reconhecido como agricultor familiar, é necessário que o mesmo tenha acesso à Declaração de Aptidão ao Pronaf (DAP), documento emitido por entidades de ATER pública, como a EMATER ou por sindicatos de trabalhadores rurais, no escopo de acesso das políticas públicas. Para isso, é necessário que o agricultor apresente documentos comprobatórios de sua atividade e documentos de posse ou arrendamento da terra. Dos agricultores entrevistados, 96,3\% possuem DAP, 
os demais ainda não tiveram acesso, pois como agricultores assentados, ainda não possuem o documento de concessão de uso da terra.

As empresas de ATER que prestam assessorias aos agricultores entrevistados são, prioritariamente o CAPA, a BIOLABORE e a EMATER, esta última é acessada em momentos pontuais. A maioria dos agricultores, 92,6\%, recebe assessoria técnica. Dos vinte e sete agricultores entrevistados, $70,4 \%$ são certificados e $29,6 \%$ estão em transição para certificação. 92,6\% dos agricultores são certificados pela Rede Ecovida de certificação participativa, destes, um agricultor indicou ser certificado pela Rede Ecovida e pelo TECPAR ${ }^{2}$ (auditoria por certificação pública). Já os demais, 7,4\%, são certificados pela ECOCERT ${ }^{3}$, que realiza certificação por auditoria privada.

Os agricultores foram questionados sobre como tiveram acesso à agricultura orgânica/agroecológica. As respostas foram variadas, sendo as seguintes:

a) através do grupo da rede (Ecovida);

b) o agricultor procurou a entidade de ATER;

c) através do Movimento dos Trabalhadores Rurais Sem Terra (MST);

d) através de programas de governo;

e) através de cursos, onde o agricultor entrou em contato com o técnico;

f) ao filiar-se na associação, passou a receber assessoria e técnica e incentivo a iniciar o processo de transição e posterior certificação;

g) quando começou a plantar grãos orgânicos, passou a ter assessoria;

h) através de convite da prefeitura;

i) via convênios (Itaipu, INCRA, Fundação Terra).

Ao optarem por praticar a agricultura orgânica/agroecológica, $78 \%$ dos entrevistados argumentaram ter sido uma decisão tomada em família; $22 \%$ sofreram influência da ATER, ou movimento social ao qual pertencem.

Sobre a divisão das tarefas na propriedade, 59,2\% dos entrevistados comentaram que não há uma distinção por gênero, informando que a família trabalha junto. Os demais, 40,8\% justificaram que há afazeres designados para cada membro da família. Porém, é notório que as mulheres têm atuado no trabalho a campo e, também na gestão

2 O TECPAR realiza certificação de produtos orgânicos, gratuitamente a agricultores, através do "Programa Paraná Mais Orgânico". GOVERNO DO ESTADO DO PARANÁ (2019).

${ }^{3}$ A ECOCERT é um organismo de inspeção e certificação por auditoria privada. 
administrativa da propriedade, e, ainda, cabe aos homens as tarefas de maior demanda braçal.

Segundo os dados levantados, as atividades de maior relevância realizadas pelas famílias entrevistadas são as seguintes, em ordem de maior citação: hortaliças, leite e derivados, grãos, frutas, agroindústrias, suínos, frangos, ovos, ovelhas e gado de corte. Das vinte e sete famílias entrevistadas, vinte e quatro comercializam sua produção, seja convencional ou orgânica/agroecológica. As outras três famílias produzem para seu autossustento ${ }^{4}$. Para o autoconsumo os entrevistados elencaram que são produzidos: carne, leite, feijão, banha, verdura, ovos, amendoim, mandioca, alho, cebola, frutas, bata doce, cará, lenha, queijo, milho e linguiça; salienta-se que o arroz de sequeiro é produzido apenas no assentamento em Cascavel. Além do mais, os agricultores de Marechal Cândido Rondon têm a possibilidade de realizar trocas de seus produtos por outros, que eles não produzem, na feira permanente, mantida pela associação de agricultores orgânicos e pela prefeitura.

Outro fator de destaque, é que as famílias entrevistadas criam animais como bovinos (leite e corte), suínos, aves (postura e corte), peixes, ovinos e abelhas. A bovinocultura é praticada por 62,9\% das famílias que criam, no total, 230 cabeças, uma média de 13,5 cab/família. Cada animal possui um valor médio de $\mathrm{R} \$ 2.044,56$ (dois mil e quarenta e quatro reais e cinquenta e seis centavos). A avicultura é praticada por 44,4\% das famílias, com uma média de $86 \mathrm{cab} /$ por família. A suinocultura é praticada por 55,5\% das famílias, com uma média de 10,8 cab/família. A apicultura é realizada por $18,5 \%$ das famílias, totalizando 12 colmeias. Com relação à piscicultura, $11,1 \%$ das famílias possuem tanques, totalizando 7 tanques, criando tilápias, pacus e carpas. Para tração animal, apenas 3,7\% das famílias indicaram utilizar cavalos para esse fim. Finalmente, 3,7\% das famílias criam ovinos, totalizando 11 animais. A pecuária pode representar uma como uma alternativa para a obtenção de renda monetária às famílias, ou apenas servir para autossustento.

\footnotetext{
${ }^{4}$ A produção para autossustento constitui-se na produção e reprodução social da identidade familiar. A produção para autossustento gera uma relativa independência econômica e social, principalmente pela diversidade de alimentos produzidos e também pela existência da reciprocidade com os vizinhos nas trocas dos produtos, sementes e conhecimentos.
} 
O produto bruto ${ }^{5}(\mathrm{~PB})$ médio anual está em torno de $\mathrm{R} \$ 13.611,70$ (treze mil, seiscentos e onze reais e setenta centavos) por família, ou seja, uma média mensal de R\$ 1.134,31 (um mil cento e trinta e quatro reais e trinta e um centavo). Deve-se levar em consideração que três famílias não comercializam e que a produção para o autoconsumo é um fato consumado entre as famílias entrevistadas. Existe também a possibilidade de que alguns agricultores não tenham apresentado o valor total de sua renda para a pesquisa, uma vez que ainda pode ser considerado um "tabu" o fornecimento dessa informação.

O cálculo do produto bruto por hectare das áreas orgânicas/agroecológicas é de $\mathrm{R} \$ 1.634,97$ (um mil, seiscentos e trinta e quatro reais e noventa e sete centavos) por hectare/mês/família; e no convencional (áreas não certificadas) foi encontrada uma média de $\mathrm{R} \$ 1.010,50$ (um mil e dez reais e cinquenta centavos) por hectare/mês/família. Portanto, percebe-se que, desconsiderando o consumo intermediário $^{6}(\mathrm{CI})$, a área orgânica/agroecológica apresenta melhores rendimentos por unidade de área. Estudos realizados no Rio Grande do Sul, por Wives (2008, 2013), analisando sistemas de produção convencionais e agroecológicos de banana demonstraram os mesmos resultados para o produto bruto por ha, ou seja, o PB superior nos sistemas agroecológicos.

Existem ainda outras duas fontes de rendimentos para as famílias entrevistadas, a agroindústria, com a produção de conservas, queijos, linguiças, pães, cucas, bolachas, vinhos, entre outros; e a exploração do turismo rural. Na agroindústria, sete famílias estão envolvidas nesta atividade, com uma renda mensal média (bruta) de R \$ 3.283,26 (três mil, duzentos e oitenta e três reais e vinte e seis centavos) por família. Três famílias exploram o turismo rural com uma renda média mensal bruta de $\mathrm{R} \$ 739,69$ (setecentos e trinta e nove reais e sessenta e nove centavos) por família.

A partir dos dados elencados, percebe-se que há uma ampla diversidade de atividades e agrobiodiversidade. Ou seja, as famílias entrevistadas desenvolvem uma

\footnotetext{
5 Produção Bruta (PB) - Representa o valor da produção em Reais gerada durante o ano, exclusivamente pela unidade de produção. $\mathrm{O}$ valor dos seguintes produtos e serviços finais compõe o PB: a produção vendida, consumida, transformada e estocada pela família; a produção destinada ao pagamento de serviços de terceiros; a variação do rebanho animal; a remuneração de serviços prestados para terceiros pela mão-de-obra familiar.

${ }^{6}$ Consumo Intermediário (CI) - Representa o valor em Reais dos insumos e serviços destinados ao processo de produção, adquiridos de outros agentes econômicos (sementes, fertilizantes, corretivos, fungicidas, energia).
} 
produção variada e, de alguma forma, buscam a diversificação da renda, seja ela monetária ou não monetária, como no caso da produção para o autoconsumo.

Figura 1 - Agrobiodiversidade representativa que compões a renda das famílias

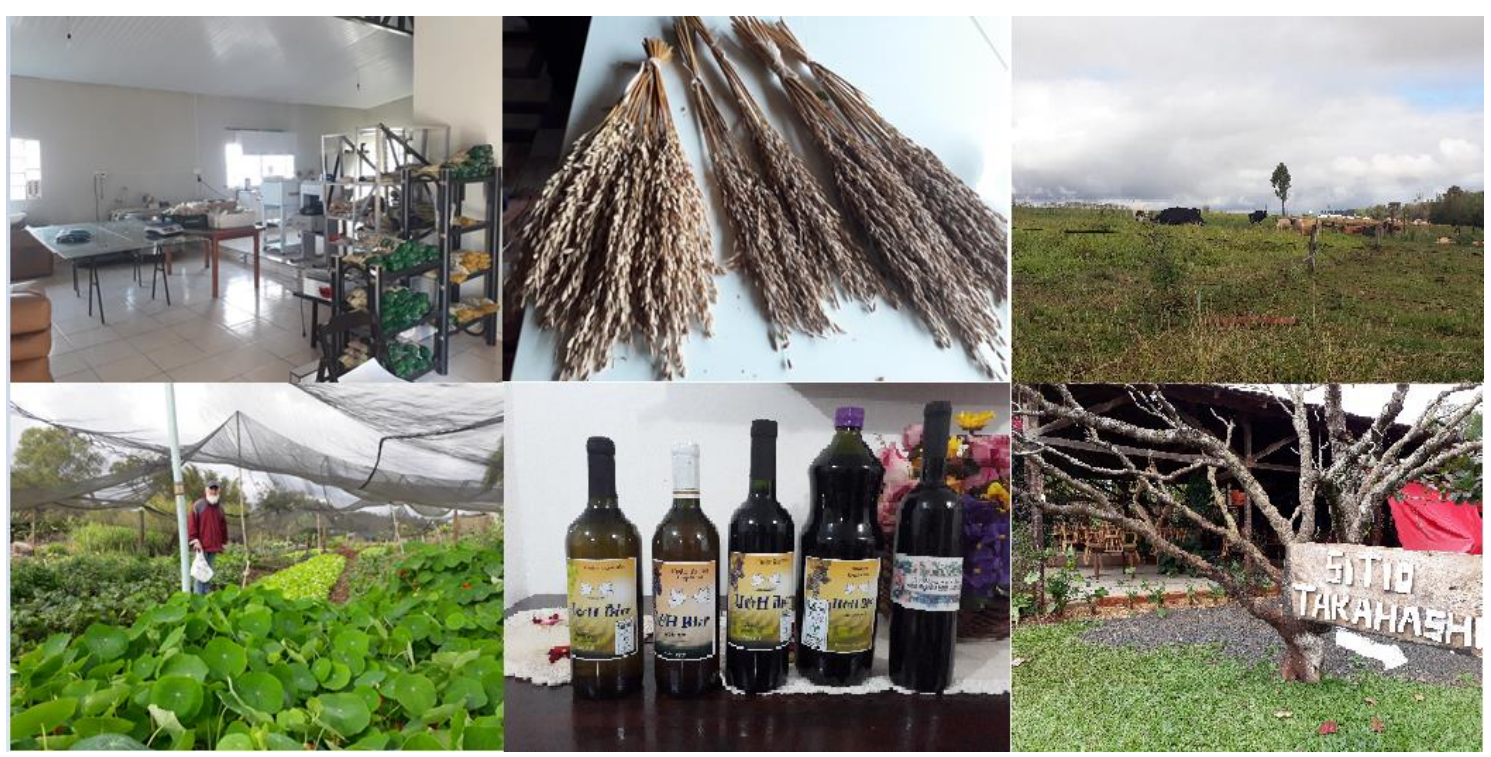

Fonte: O autor (2019).

A Figura 1 demonstra a diversidade dos sistemas de produção que compõe os rendimentos financeiros dos agricultores. $\mathrm{Na}$ imagem é possível observar as agroindústrias, produção vegetal, produção animal, o resgate de sementes crioulas, no caso do arroz, e o turismo rural.

Agroecologia e transição - o ponto de vista dos agricultores

Esta seção ilustrará qual a concepção dos agricultores entrevistados a respeito da agricultura orgânica/agroecológica e como foi o processo de adesão a esta prática de produção, buscando compreender quem os influenciou nessa iniciativa e o que os motiva a permanecerem nesse sistema produtivo.

A percepção dos agricultores sobre o que entendem por agricultura orgânica/agroecológica revela distintos caminhos. Entretanto, observou-se principalmente a ligação estabelecida com as questões de saúde, o respeito ao consumidor, uma postura/projeto de vida, o respeito ambiental, o retorno econômico, o 
ponto de vista religioso e uma missão de vida, conforme o relato a seguir de um agricultor de Marechal Cândido Rondon:

“[AGRICULTOR-MARECHAL CÂNDIDO RONDON]. Outro jeito de viver e pensar, um projeto de vida, qualidade vida, saúde, modo de vida, dar valor à terra. A terra é dada por Deus para o homem produzir alimento. Viver em harmonia com a natureza. Querer o melhor para mim e minha família e também para o vizinho e para os outros. Forma de vida mais saudável. Projeto, plano de vida saudável, projeto de vida, considerando todos os seres vivos que a compõem”.

Em síntese, os agricultores definiram a agricultura orgânica/agroecológica como um sistema de produção em que a relação do ser humano com o meio ambiente/natureza é respeitada, corroborando com os conceitos de Costabeber (1998) e Sevilha Guzmán (1999), apresentados anteriormente nesta pesquisa. Destarte, a agroecologia é um sistema autossustentável da agricultura, uma técnica mais moderna, que "não usa veneno", como pode ser aduzido na entrevista a seguir:

“[AGRICULTOR- SÃO MIGUEL DO IGUAÇU] $O$ mundo está pedindo práticas menos agressivas; a retomada de conhecimento dos antepassados. Um trabalho sem agrotóxico. Uma continuidade do serviço do campo para o homem sobreviver no campo. Produzindo o convencional não tinha retorno para viver no sítio... A possibilidade de viver apenas da terra, sem precisar trabalhar fora. O fato de dar uma lucratividade maior, por conta de se utilizar menos insumos."

Nesta pesquisa, também se buscou conhecer como se deu o processo de transição da agricultura convencional para a agricultura orgânica/agroecológica. Nesse sentido, foi consenso entre os entrevistados de que a transição se trata de um período delicado, que exige adaptação, resistência, educação e conscientização de agricultores e consumidores.

Sobre esse ponto, na Figura 2, encontra-se o croqui de uma propriedade desenhado por uma das famílias entrevistadas. Neste croqui, percebe-se que a família tem plena percepção dos talhões que compõem a propriedade e da necessidade de se delimitar a área de produção orgânica/agroecológica com barreiras como forma de proteção contra agentes contaminante oriundos de plantações vizinhas, não certificadas. 
Figura 2 - Croqui da propriedade conforme a percepção de um agricultor de Cascavel

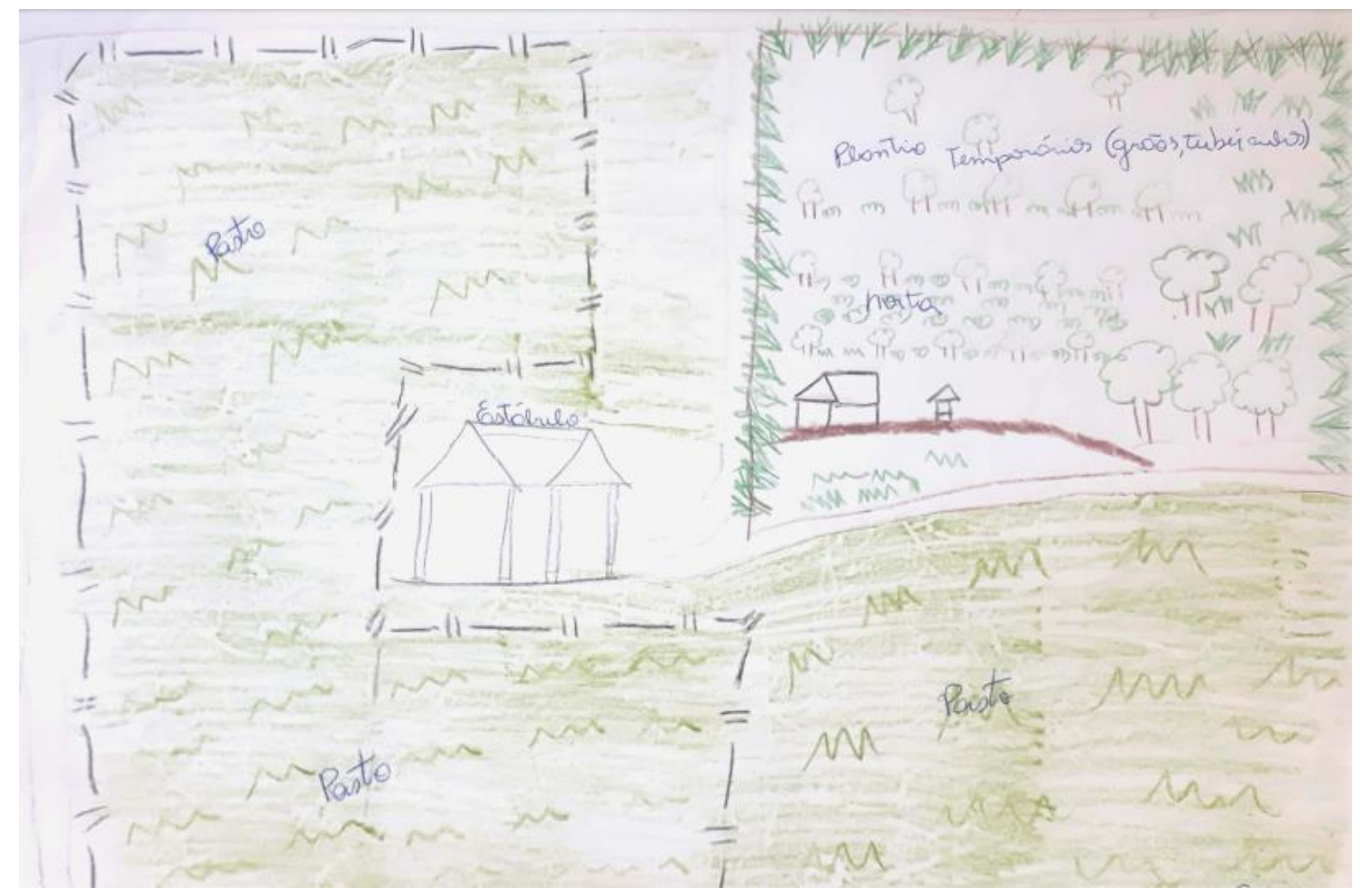

Fonte: Dados da pesquisa (2019).

Os croquis demonstram as diferentes interpretações relacionadas a sua auto interpretação diante de suas propriedades, bem como, auxiliam na compreensão do que o agricultor(a) pretendem expor durante as entrevistas.

Para alguns produtores, o processo de transição, pode ter significado apenas uma troca de insumos, do químico sintético para insumos orgânicos, permitidos pela legislação. Porém, o processo de transição é motivado por vários fatores, inclusive, alguns ligados a crises na família, de ordem econômica e de saúde, até mesmo por questões subjetivas e influência de movimentos sociais ou programas, como o "Cultivando Água Boa", da Itaipu, ou o incentivo da rede de ATER, estes últimos programas influentes e atuantes, até os anos de 2016, após esse período e com a extinção da Ministério do Desenvolvimento Agrário tiveram sua expressão em muito diminuídas, quase extintas. Outro fator que motivou a transição está ligado às estratégias comerciais, como parar de fornecer produtos nas Centrais de Abastecimento (CEASA) e comercializar direto com o consumidor, a possibilidade em diversificar a produção e a demanda da sociedade por produtos saudáveis. Por fim, fatores como a influência de antepassados, a possibilidade 
de sucessão familiar e a não adaptação à ATER convencional também foram citados como motivos para a transição para a agricultura orgânica/agroecológica.

A pesquisa mostrou que $26 \%$ dos agricultores não usavam agrotóxicos antes de iniciarem a certificação de sua produção como orgânica/agroecológica. Outros 14,8\% não responderam a esta questão e os demais, 59,2\%, indicaram que utilizavam agrotóxicos anteriormente. Como práticas alternativas, que ajudam a se manter na agricultura orgânica/agroecológica, estão os cursos oferecidos pelas entidades de ATER para dominar técnicas como o feitio de caldas, o uso da homeopatia, extratos vegetais, a fertilidade da terra e plantas, conhecimento ecológico sobre plantas que atraem e repelem insetos e armadilhas para insetos.

Outras práticas, adotadas pelos agricultores entrevistados, que são rotineiras numa produção orgânica/agroecológica, foram a adubação verde, a rotação de culturas, as barreiras vegetais permanentes e temporárias, a utilização de sementes crioulas, a realização de podas, a utilização de produtos biológicos, como microrganismos eficientes, biofertilizantes, não revolver o solo, a indução da resistência das plantas, aprender a correção do solo através da "leitura" das plantas, o plantio direto e a ausência de queimadas.

O papel da ATER e do extensionista na agricultura orgânica/ agroecológica do ponto de vista dos agricultores

Para o desenvolvimento da agricultura orgânica/agroecológica na região oeste do Paraná, ficou clara a importância do envolvimento de diversas entidades. Neste sentido, os entrevistados nomearam dezesseis entidades parceiras que atuam ou atuaram na região, promovendo a agricultura orgânica/agroecológica. Os agricultores tiveram a liberdade de citar quantas entidades lembrassem como parceiras, e a partir destas citações, as entidades foram enumeradas, conferindo-lhe o número de vezes que cada uma foi citada no Gráfico 2. 
Gráfico 2 - Instituições parceiras citadas pelos agricultores

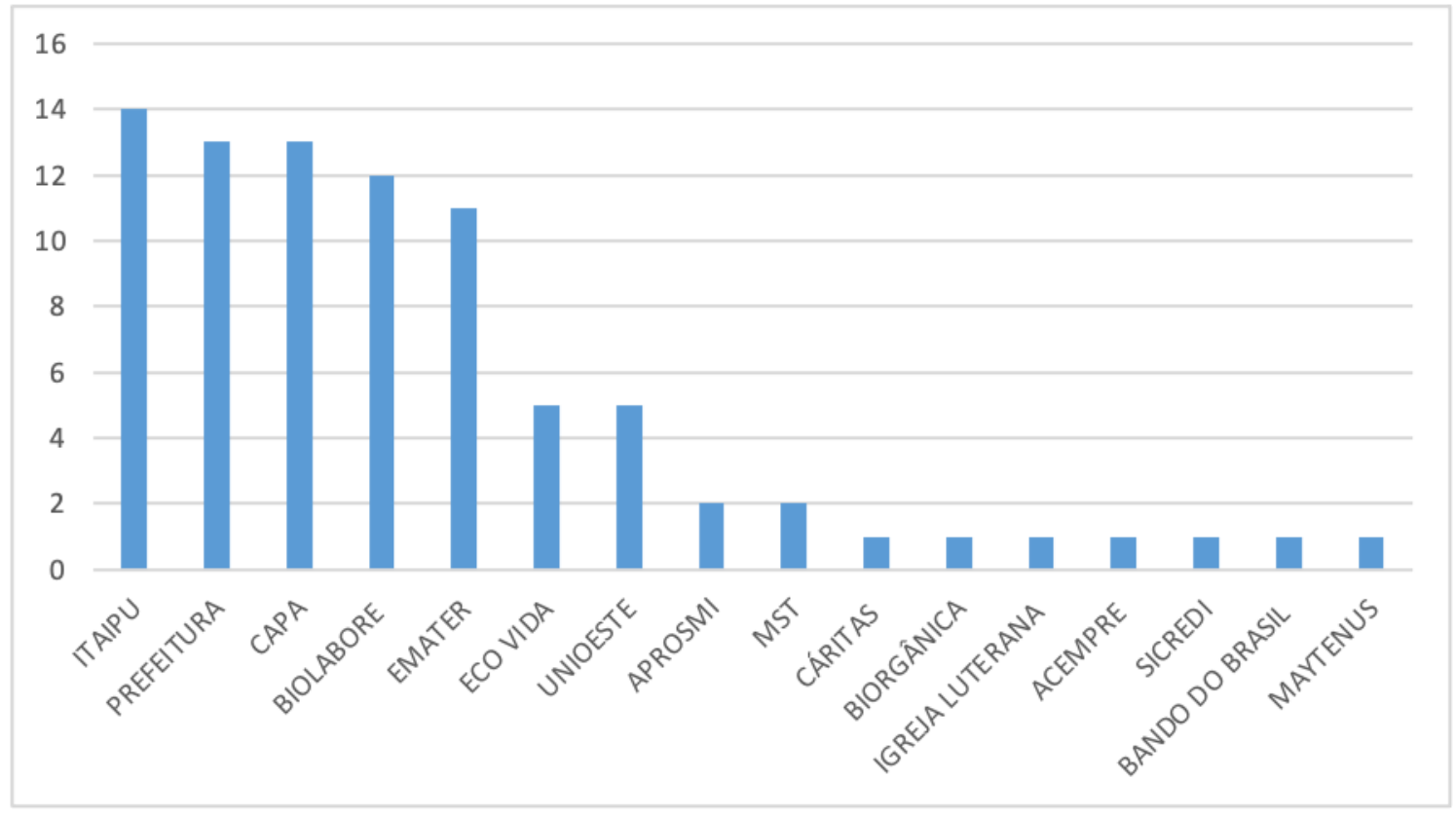

Fonte: O autor (2019).

Essa lista tão ampla de entidades nomeadas, comprova que para o agricultor, a agricultura orgânica/agroecológica realmente necessita de apoio de entidades, que dependem de recurso público para o seu desenvolvimento na região oeste do Paraná. As entidades mais citadas foram Itaipu Binacional, seguida das prefeituras e do CAPA, da BIOLABORE, da EMATER. A Itaipu Binacional é reconhecida como a provedora das ações ligadas à agricultura orgânica/agroecológica na região, uma vez que vem citada antes mesmo das entidades de ATER, as quais, por meio de seus extensionistas, estão em contato direto e cotidiano com os agricultores.

Esta pesquisa buscou entender, qual a visão do agricultor sobre a importância da assistência técnica e, fundamentalmente, o papel do extensionista no desenvolvimento da agricultura orgânica/agroecológica nas propriedades estudadas. A seguir, é possível vislumbrar as indicações de funções da ATER e extensionistas reconhecidas pelos agricultores:

a) Trocar experiências e conhecimentos;

b) Promover um sistema de produção sustentável;

c) Fazer visita de rotina e solucionar problemas (orientação técnica);

d) Realizar cursos e reuniões;

e) Ser interlocutor do processo de produção; 
f) Organizar a produção, a comercialização e agregar valores aos produtos;

g) Trazer agricultores convencionais para a agricultura orgânica/agroecológica;

h) Realizar projetos de acesso ao crédito;

i) Abrir novos horizontes;

j) Motivar o agricultor;

k) Ajudar no planejamento e traçar metas;

1) Auxiliar em toda a cadeia produtiva;

m) Trazer sementes.

Percebe-se, a partir dessa lista, que os agricultores remetem à extensão uma gama de responsabilidades para que o desenvolvimento da agricultura orgânica/agroecológica seja possível. Não é esperado do extensionista apenas orientações a respeito da produção e solução de problemas ligados à produtividade. Também é considerada como função do extensionista e, por consequência, da ATER, toda a articulação de comercialização, agregação de valores, visualização de oportunidades, busca por crédito e atrair mais agricultores interessados em fazer agricultura orgânica/agroecológica. Entende-se, portanto, que todas essas responsabilidades não estão apenas na pessoa do extensionista em campo, mas também nas entidades e nas parcerias reconhecidas pelos agricultores.

\section{Limites e potencialidades dos extensionistas e da ATER}

A partir dos dados expostos até aqui, percebe-se que desenvolver uma agricultura orgânica/agroecológica enfrenta diversos limites, seja qual for o agente envolvido. Buscou-se compreender, a partir da perspectiva do agricultor, quais são os fatores limitantes na atividade agrícola, conforme apresenta o Quadro 1. 
Quadro 1 - Limites para a agricultura orgânica/agroecológica, conforme a opinião dos agricultores.

\begin{tabular}{|c|c|}
\hline 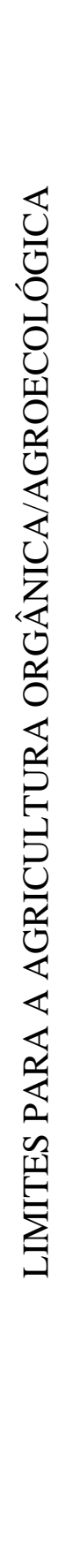 & $\begin{array}{l}\text { Falta de investimento público; } \\
\text { Dificuldade na comercialização, entrar nas feiras e outros espaços de } \\
\text { comercialização; } \\
\text { Falta de estrutura; } \\
\text { Falta de projetos; } \\
\text { Falta ATER individual específica; } \\
\text { Preconceito a quem produz agroecológicos, falta de conscientização das } \\
\text { pessoas; } \\
\text { Limitação na mão de obra; } \\
\text { Controle de erva daninha e insetos; } \\
\text { Manter a fertilidade do solo; } \\
\text { Não ter acesso a crédito (nos assentamentos); } \\
\text { Problemas de aplicação de 2,4D dos vizinhos - deriva de agrotóxico na área } \\
\text { orgânica/agroecológica; } \\
\text { Demora para implantar uma barreira efetiva; } \\
\text { Mídia do agronegócio; } \\
\text { Dificuldade em trabalhar no coletivo; } \\
\text { Dificuldade em certificar a produção animal, faltam alimentos orgânicos para } \\
\text { os animais; } \\
\text { O mercado não valoriza o produto orgânico; } \\
\text { Dificuldade na sucessão familiar, os jovens não querem ficar no campo; } \\
\text { Falta de insumos liberados para a produção orgânica; } \\
\text { Dificuldade de acesso a maquinário adequado; } \\
\text { O consumidor acha caro o preço do produto orgânico; } \\
\text { Faltam sementes/mudas orgânicas no mercado; } \\
\text { Precisa mais agroindústria para conservar a produção; } \\
\text { Deveriam existir projetos em que se adquirissem estruturas (cisternas/estufas) } \\
\text { que pudessem ser pagas com produtos na merenda escolar; } \\
\text { Assistência Técnica; } \\
\text { Relações internas nas associações; } \\
\text { Ter autonomia em informações e qualificações. }\end{array}$ \\
\hline
\end{tabular}

Fonte: $\mathrm{O}$ autor (2019).

Fica evidente, com as respostas apresentadas, que existem dificuldades dentro dos agroecossistemas, correlacionados à produção, mão de obra, insumos, controle e manejo. Há muita dificuldade relacionada ao poder público, às estruturas, à comercialização, à agroindustrialização, à aquisição de insumos permitidos, entre outros 
agravantes. Ou seja, apresenta-se grande fonte de possibilidades de investimentos, tanto do poder público, quanto do poder privado, para o desenvolvimento da agricultura orgânica/agroecológica. Para representar os pontos expostos, selecionamos o que disse um dos agricultores de São Miguel do Iguaçu ao responder a essa questão:

“[AGRICULTOR-SÃO MIGUEL DO IGUAÇU] Um dos problemas que a gente tem é a questão do conhecimento para resolver os problemas com as pragas e tudo mais que tem no lote. A gente precisa buscar fora esse conhecimento e, muitas vezes, a gente não tem acesso às políticas públicas que podem ajudar a resolver isso. Então, é muita dificuldade principalmente com relação a esse conhecimento, precisamos voltar a ter o hábito de guardar nossa própria semente, ter nossa própria base de remédios. Tudo isso foi tirado no período dos nossos ancestrais e fomos perdendo esse conhecimento. Essa é a lógica do mercado, querer acabar com nosso conhecimento e 'empurrar' outras coisas que eles têm. Muitas vezes temos em casa o que precisamos, mas vamos no mercado buscar um outro produto. Precisamos ir nos qualificando dentro da propriedade para sair do sistema de dependência. Outro problema é com relação às formigas cortadeiras, não consigo mais controlar elas e elas atacam tudo, comeram boa parte dos meus citros. Tive alguns momentos internos dentro do assentamento; com a assistência técnica melhoramos muito, principalmente na pecuária leiteira. Melhoramos a pastagem, corrigimos o solo, aumentamos a produção, então isso foi fundamental. A participação do técnico não é só de vir na sua casa te visitar, dar um bom dia e boa tarde e ir embora. O técnico é importante para além disso, a visita dele na sua propriedade é para dar um novo olhar, a estimular o agricultor a buscar coisas novas. Geralmente, quem está na propriedade não vê as falhas e é preciso alguém de fora para mostrar isso para a gente. Então é para isso que é importante a assistência técnica, porque observa aquilo que a gente não observa no nosso cotidiano. Mas claro, não é só isso, existem muitas outras contribuições que a assistência técnica nos dá. Fazemos agroecologia para a gente e não para os outros... Teve um dia que um vizinho falou que o meu lote era só capoeira e que não ia cinco anos para eu deixar de ser agroecológico, falando que a gente não produzia nada, que só estava em cima dele e ficou falando... mas agroecologia não são só valores e lucros, agroecologia é muito também da qualidade de vida." 
Assim como limites, a produção orgânica/agroecológica também apresenta potencialidades. Os agricultores entrevistados foram desafiados a elencar as principais potencialidades, as quais estão listadas no Quadro 2.

Quadro 2 - Potencialidades da agricultura orgânica/agroecológica, segundo o ponto de vista dos agricultores

\begin{tabular}{|c|c|c|}
\hline & 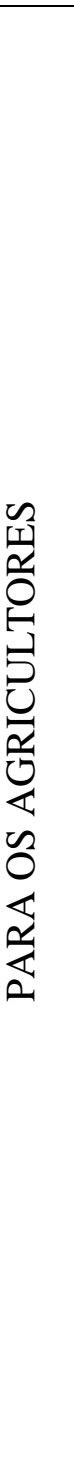 & $\begin{array}{l}\text { Uma relação de respeito com a terra, com a natureza e com as pessoas; } \\
\text { Oportunidade de dar um futuro diferente aos filhos; } \\
\text { Reaproveitamento de resíduos que se tem no sítio na própria produção; } \\
\text { Não depender do mercado, produzir para o autossustento; } \\
\text { É a saída para a produção de alimentos no Brasil e no mundo - referindo- } \\
\text { se à necessidade ecológica de se tornar cada vez mais sustentável; } \\
\text { A diversificação da produção; } \\
\text { Acreditar em si próprio, motivado pelo bem viver; } \\
\text { Boas vendas com preço melhor (preço mais justo ao agricultor); } \\
\text { Reconhecimento do consumidor, receber elogios do cliente; } \\
\text { Fidelizar clientes; } \\
\text { Menor impacto de crises econômicas; } \\
\text { Insumos mais baratos (semente de soja da Guebana é mais barata que a } \\
\text { convencional); } \\
\text { Menor risco de intoxicação do agricultor; } \\
\text { A demanda por produtos orgânicos está aumentando; } \\
\text { A possibilidade de produzir algo mais específico como o macarrão } \\
\text { orgânico ou a folha da taioba; } \\
\text { A conscientização que vem sendo feita sobre alimentação saudável; } \\
\text { Ser um exemplo de agricultor e de agricultura, inspirar as pessoas. }\end{array}$ \\
\hline
\end{tabular}
Fonte: O autor (2019).

Percebe-se que alguns fatores limitantes e potencialidades são pontos em comum, ou seja, algumas questões que são limites para alguns, são potencialidades para outros. Esse fato pode estar ligado ao município como, por exemplo, a dificuldade em acessar feiras em Cascavel, ou a questão do preço do produto que, para alguns se 
apresenta como um limitante para a inserção de produtos no comércio e, para outros, significa um aporte na renda familiar. De qualquer maneira, os aspectos limitantes e as potencialidades apontam para a necessidade em se pensar a agricultura orgânica/agroecológica em toda sua totalidade contemplado múltiplos de seus aspectos e valorizando sua organização em cadeias curtas, que se estabelece nas relações de confiança desde o cultivo até a chegada ao consumidor.

Questionou-se os agricultores se eles consideram a agricultura orgânica/agroecológica um modelo viável para o futuro e dos vinte e sete entrevistados, 92,5\% acreditam que sim e o restante, 7,5\% não respondeu a esta questão. O que mostra que, apesar de qualquer fator limitante, existe nesses agricultores algo para além de aspectos econômicos, algo ligado à qualidade de vida e dos alimentos. Enfím, o como e o que se produz tornam-se muito importante, como podemos observar no depoimento abaixo:

“[AGRICULTOR-PALOTINA] Muito viável. É uma questão de necessidade. A Dinamarca, que se tornou $100 \%$ orgânica, acho que esse é um lado interessante. Todo mundo focado em um mesmo objetivo, ajuda muito. Mas, ainda tem muito para crescer. O que precisa mudar é a mentalidade das pessoas, muita gente prefere pagar barato e não saber o que é."

Resultados semelhantes foram encontrados por Martinelli, Armstrong e Cordeiro (2016) ao afirmarem que os agricultores da Associação dos Produtores Orgânicos de Palotina (APOP) mostravam-se otimistas em continuar com a produção orgânica, entendendo que o trabalho de divulgação e conscientização precisa se expandir e atrair mais o consumidor, aumentando a renda do agricultor e promovendo a agricultura orgânica/agroecológica na sociedade.

\section{Considerações finais}

A presente pesquisa buscou fazer uma reflexão sobre o desenvolvimento da agricultura orgânica/agroecológica vinculada agricultura familiar, na região oeste do Paraná, elencando os desafios, motivações e oportunidades, no que tange aos aspectos ecológicos, econômicos e sociais desta atividade. Tal estudo tem como temática central as diferentes percepções da agricultura orgânica/agroecológica, partindo da análise de 
vivencias de agricultores, extensionistas e instituições públicas/privadas de Assistência técnica e extensão rural (ATER), que prestam serviços de promoção à agricultura orgânica/agroecológica.

Este estudo demonstrou que a implantação de um novo modelo de produção não se consolida através de métodos usuais, com metas de imposição, e sim através de um trabalho lento e paciente, em que o agricultor precisa compreender na prática a eficácia da agricultura orgânica/agroecológica para poder desenvolvê-la.

$\mathrm{Na}$ ascensão dessa abordagem, devemos considerar que os agricultores familiares agroecologistas, ou em processo de transição agroecológica, possuem concepções e conhecimentos ancestrais quanto aos usos, valores e manejo de um agroecossistema. Essas concepções variam desde aspectos ecológicos, culturais e sociais, norteados pelas distintas necessidades e interesses de cada um, entendendo que os agricultores familiares percebem a agroecologia como oportunidade de geração de vida e do bem viver, a partir da relação homem-natureza-agricultura, ao passo em que se torna uma estratégia importante de reprodução social.

Foi feita uma caracterização dos agricultores entrevistados, trazendo informações sobre questões ambientais, sociais, econômicas e a respeito da vivência com a agricultura orgânica/agroecológica. Com relação aos agricultores, percebe-se que ainda há questões ambientais/sanitárias a serem resolvidas, relacionadas ao uso da água para consumo (água tratada) e para a agropecuária (acesso dos animais a cursos d'água), bem como o destino correto do lixo doméstico. Este ponto está ligado também ao envolvimento do estado na promoção de campanhas educativas e também, na eficiência da coleta e destino do lixo que, muitas vezes, não ocorre no meio rural.

Esta pesquisa evidenciou que um número significativo das famílias atendidas realiza "práticas agroecológicas", não demonstrando interesse pelo processo de transição e certificação dos seus produtos. Tal fato justifica-se pela recusa do agricultor em lidar com processos burocráticos e com a necessidade em participar de reuniões e outros eventos promovidos pela certificadora. Este número sugere que, há possibilidade de a produção orgânica/agroecológica ser maior, porém invisibilizada por não estar certificada.

Os agricultores demonstram ter clareza dos limites da atividade, listando fatores em diversos níveis, como legislação, relações governamentais e assuntos técnicos. No 
entanto, percebe-se que ainda reportam à ATER responsabilidades para além da assessoria técnica, agregando papeis relacionados à entidade, ao poder público e a eles próprios, no sentido da organização da produção de acesso aos mercados. O fato de os agricultores entrevistados estarem em média há dez anos na agricultura orgânica, demonstra que as entidades de ATER promoveram a agricultura orgânica/agroecológica, pois as três entidades analisadas passaram a atuar há mais de dez anos na região pesquisada.

Perante o exposto, percebe-se também o desenvolvimento da agricultura orgânica/agroecológica ainda é muito dependente de políticas públicas para sua consolidação. A política pública que mais mobiliza a atividade é o PNAE, pois remunera melhor o agricultor que entrega o produto com certificado orgânico, fazendo com que produtores procurem este trabalho específico, na busca pela melhoria de sua renda isso principalmente até a ano de 2019. Por fim, a correlação de forças com o agronegócio na região representa um entrave poderoso para o avanço da agricultura orgânica/agroecológica, uma vez que seus pacotes tecnológicos parecem ser mais efetivos e rápidos em seu modo de ação.

No entanto, vale ressaltar, que a Itaipu Binacional, representa o diferencial na possibilidade de ATER, diferente das demais regiões do Estado e do país. Caberia, neste quesito, um aprofundamento na pesquisa, para apurar, se realmente a presença da Itaipu Binacional interfere na promoção e no desenvolvimento da agroecologia, quando comparada à outras regiões que não possuem esta oportunidade; e quais as possibilidades de sustentação das entidades de ATER sem o recurso público, prestando assessoria privada em agricultura orgânica/agroecológica. Inclusive, ressalta-se que, mesmo a EMATER, que é uma entidade governamental, também alega que o trabalho depende de chamadas públicas que ampliem o foco de trabalho na empresa.

\section{REFERÊNCIAS}

ALTIERI, M. Agroecologia: bases científicas para uma agricultura sustentável. 3. ed. São Paulo: Expressão Popular; Rio de Janeiro: AS-PTA, 2012.

BRASIL. Decreto no 7.794, de 20 de agosto de 2012. Institui a Política Nacional de Agroecologia e Produção Orgânica - PNAPO. Brasília, DF, 2012. Disponível em: http://bit.ly/2NxMfr6. Acesso em: 18 dez. 2019. 
BRASIL. Ministério da Agricultura, Pecuária e Abastecimento. Instrução Normativa nº46 de 2011 (produção vegetal e animal) regulada pela IN 17-2014. Brasília, DF, 2011. Disponível em: http://bit.ly/2JKqzXT. Acesso em: 24 mar. 2019.

BRASIL. Presidência da República. Lei no 10.831, 23 de dezembro de 2003. Dispõe sobre a agricultura orgânica e dá outras providências. Brasília, DF, 2003. Disponível em: http://bit.ly/2C88a2U. Acesso em 25 fev. 2019.

BRASIL, PRESIDÊNCIA DA REPÚBLICA. Lei no 10.831, 23 de dezembro de 2003 Dispõe sobre a agricultura orgânica e dá outras providências. Disponível em: <http://www.planalto.gov.br/ccivil_03/LEIS/2003/L10.831.htm> Acesso em 25/02/2019.

CAPORAL, F. R. Poderá a Agroecologia responder aos cinco axiomas da sustentabilidade? Rev. Bras. de Agroecologia, v. 11, n. 4, p. 390-402, 2016.

COSTABEBER, J. A. Acción colectiva y procesos de transición agroecológica en Rio Grande do Sul, Brasil. 1998. 422f. Tese (Doctorado en Agroecología) - Programa de Doctorado en Agroecología, Campesinado e Historia, Universidad de Córdoba, España, 1998.

CRESWELL, J. W. Projeto de pesquisa: métodos qualitativo, quantitativo e misto. $3^{\mathrm{a}}$ ed. Porto Alegre: Artmed, 2009.

GRISA, C. A agricultura familiar nas políticas para a agricultura familiar. In: Delgado, Guilherme Costa; Bergamasco, Sonia Maria Pessoa Pereira (Orgs.) Agricultura familiar brasileira: desafios e perspectivas de futuro. Brasília: Ministério do Desenvolvimento Agrário, 2017.

GRISA, C.; SCHNEIDER, S. Três gerações de políticas públicas para a agricultura familiar e formas de interação entre sociedade e Estado no Brasil. In:

Políticas Públicas de Desenvolvimento Rural no Brasil. Porto Alegre: Editora da UFRGS, 2015.

GONZALEZ DE MOLINA, M. Las experiencias agroecológicas y su incidencia en el desarrollo rural sostenible. La necesidad de una agroecológica política. In: SAUER, S.; BALESTRO, M. V. (orgs.). Agroecologia e os desafios da transição agroecológica. São Paulo: Expressão Popular. 2009. p. 17-70.

GUZMÁN, E. S. Assentamientos rurales y agroecología em Andalucía. España: ISEC Universidade de Córdoba, 1999.

GUZMÁN, E. S Agroecologia e desenvolvimento rural sustentável. In: AQUINO, A. M.; ASSIS, R. L. (orgs.). Agroecologia: Princípios e técnicas para uma agricultura orgânica sustentável. Rio de Janeiro: Embrapa Agrobiologia, 2006. p. 101-1316. 
HAVERROTH, C. Extensão Rural Pública: Métodos, Possibilidades e Limites para a Transição Agroecológica no Oeste Catarinense. Dissertação (Mestrado em Extensão Rural) - Universidade Federal de Santa Maria, Santa Maria. 2012.

IPARDES - INSTITUTO PARANAENSE DE DESENVOLVIMENTO ECONÔMICO E SOCIAL. Leituras Regionais: Mesorregião geográfica oeste paranaense. Curitiba: Imprensa Oficial, 2010.

ITAIPU BINACIONAL. Cultivando água boa. 2018. Disponível em: http://bit.ly/2PHeYww. Acesso em: 07 fev. 2019.

MINISTÉRIO DA AGRICULTURA, DESENVOLVIMENTO E PECUÁRIA - MAPA. Cadastro Nacional de Agricultores Orgânicos. Disponível em:< http://www.agricultura.gov.br/assuntos/sustentabilidade/organicos/cadastro-nacionalprodutores-organicos>. Acesso em: 08 de fevereiro de 2019.

MARTINELLI, J. V.; ARMSTRONG, C. J.; CORDEIRO, J. Aspectos socioeconômicos da produção de alimentos orgânicos em Palotina PR. Revista Cultivando o Saber, v. 9, n. 3, p. 318-336, jul./set. 2016.

PARANÁ. Governo do Estado. Programa mais orgânico - certificação. 2009. Disponível em: http://bit.ly/2qeqxAA. Acesso em: 24 mar. 2019.

REDE DE AGROECOLOGIA ECOVIDA. Sobre. 2018. Disponível em: http://bit.ly/2r3c4Yp. Acesso em: 24 mar. 2019.

SCHNEIDER, S.; CASSOL, A. Diversidade e heterogeneidade da agricultura familiar no Brasil e implicações para políticas públicas. Seminário Nacional Agricultura Familiar Brasileira - desafios e perspectivas de futuro. Brasília, v. 13, v. 2, p. 227-263, mai/ago. 2014.

VERGARA, S. C. Métodos de pesquisa em administração. São Paulo: Atlas, 2005.

WIVES, D. G. Funcionamento e performance dos sistemas de produção da banana na Microrregião do Litoral Norte do Rio Grande do Sul. Dissertação (Mestrado em Desenvolvimento Rural) - Faculdade de Ciências Econômicas, Universidade Federal do Rio Grande do Sul, Porto Alegre, 2008.

WIVES, D. G. Fatores Influentes na Tomada de Decisão e Organização dos Sistemas de Produção da Base Ecológica da Banana no Litoral Norte do Rio Grande do Sul. Tese (Doutorado em Desenvolvimento Rural) - Faculdade de Ciências Econômicas, Universidade Federal do Rio Grande do Sul, Porto Alegre, 2013.

Recebido em 13/05/2021.

Aceito para publicação em 17/09/2021. 